\title{
MANUFACTURING DEVELOPMENT OF LOW ACTIVATION VANADIUM ALLOYS
}

\author{
by \\ J.P. SMITH, W.R. JOHNSON, and C.B. BAXI
}

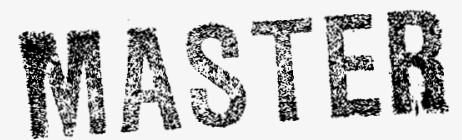

OCTOBER 1996 


\section{DISCLAMMER}

Portions of this document may be illegible in electronic image products. Images are produced from the best available original document. 


\title{
MANUFACTURING DEVELOPMENT OF LOW ACTIVATION VANADIUM ALLOYS
}

\author{
by \\ J.P. SMITH, W.R. JOHNSON, and C.B. BAXI
}

This is a preprint of a paper to be presented at the 12th Topical Meeting on The Technology of Fusion Energy, June 16-20, 1996, Reno, Nevada and to be published in the Proceedings.

\author{
Work supported by \\ the U.S. Department of Energy \\ under Contract No. DE-AC03-89ER51114
}

\section{GA PROJECT 3466 \\ OCTOBER 1996}




\section{MANUFACTURING DEVELOPMENT OF LOW ACTIVATION VANADIUM ALLOYS}

\author{
J.P. Smith \\ General Atomics \\ P.O. Box 85608 \\ San Diego, California 92186-9784 \\ (619) 455-3836
}

\author{
W.R. Johnson \\ General Atomics \\ P.O. Box 85608 \\ San Diego, California 92186-9784 \\ (619) $455-2905$
}

\author{
C.B. Baxi \\ General Atomics \\ P.O. Box 85608 \\ San Diego, California 92186-9784 \\ (619) 455-3501
}

\begin{abstract}
General Atomics is developing manufacturing methods for vanadium alloys as part of a program to encourage the development of low activation alloys for fusion use. The culmination of the program is the fabrication and installation of a vanadium alloy structure in the DIII-D tokamak as part of the Radiative Divertor modification. Water-cooled vanadium alloy components will comprise a portion of the new upper divertor structure. The first step, procuring the material for this program has been completed. The largest heat of vanadium alloy made to date, $1200 \mathrm{~kg}$ of $\mathrm{V}-4 \mathrm{Cr}-4 \mathrm{Ti}$, has been produced and is being converted into various product forms. Results of many tests on the material during the manufacturing process are reported. Research into potential fabrication methods has been and continues to be performed along with the assessment of manufacturing processes particularly in the area of joining.
\end{abstract}

Joining of vanadium alloys has been identified as the most critical fabrication issue for their use in the Radiative Divertor Program. Joining processes under evaluation include resistance seam, electrodischarge (stud), friction and electron beam welding. Results of welding tests are reported. Metallography and mechanical tests are used to evaluate the weld samples. The need for a protective atmosphere during different welding processes is also being determined.

General Atomics has also designed, manufactured, and will be testing a helium-cooled, high heat flux component to assess the use of helium cooled vanadium alloy components for advanced tokamak systems. The component is made from vanadium alloy tubing, machined to enhance the heat transfer characteristics, and joined to end flanges to allow connection to the helium supply. Results are reported.

\section{INTRODUCTION}

To realize the environmental benefits of fusion energy, low activation materials must be utilized. The development of these materials has been proceeding in the U.S. and throughout the world. In the U.S., the primary work has been performed under the auspices of the Materials Program of the Department of Energy's Office of Fusion Energy Sciences from which vanadium alloys have been identified as the leading fusion structural material based on their high temperature capability and irradiation performance (stability). While vanadium is a fairly common element, it is primarily used as an alloying element in steels. Outside the fusion program, uses of vanadium alloys' unique characteristics have not been identified and thus development of the alloys has proceeded only within the fusion program. The production and fabrication of vanadium alloys has been primarily limited to small research heats to study alloy composition and irradiation stability with no development of components. The largest heat of vanadium alloy produced in the U.S. before the present effort was $500 \mathrm{~kg}$ with all others well below $100 \mathrm{~kg}$. To date, no significant components have been made from vanadium alloys although some pure vanadium components were made as part of the nuclear weapons programs.

\section{UTILIZATION OF VANADIUM IN DIII-D}

To enhance the development of low activation alloys for fusion applications, General Atomics, along with Argonne National Laboratory (ANL) and Oak Ridge National Laboratory (ORNL), has written and is 
implementing a plan for the utilization of vanadium alloys in the DIII-D tokamak. This plan will culminate in the fabrication, installation, and operation of a vanadium alloy structure as part of the DIII-D Radiative Divertor Program (RDP) (Fig. 1). The use of vanadium in DIII-D provides a meaningful step towards advancing development of low activation materials for fusion power applications by 1) demonstrating the in-service behavior of a vanadium alloy in a typical tokamak environment, and 2) developing knowledge and experience on design, processing, and fabrication of full-scale vanadium alloy components.

The program consists of three phases: (1) expose small vanadium alloy specimens and coupons in DIII-D; (2) design, manufacture and test a small vanadium alloy component in conjunction with the existing DIII-D divertor; and (3) design, manufacture, and install the structure for the private flux baffle of the new double-null, slotted divertor from vanadium alloy. A major portion of the program supports fabrication of the material and product forms, and development of welding processes to complete the manufacture of the components. The plan is being carried out in conjunction with General Atomics, the DIII-D Program, and the Materials Program of the Department of Energy's Office of Fusion Energy, primarily ANL, ORNL and Pacific Northwest National Laboratory (PNNL).

\section{A. Phase 1: Specimen And Coupon Exposures And Analysis}

In March of 1995, miniature Charpy V-notch (CVN) impact and tensile specimens of vanadium alloy were installed in DIII-D in positions behind the divertor baffle, away from energetic particles, for long-term exposure $(\sim 1$ year). ANL supplied the samples, and General Atomics designed, fabricated and installed the sample holder. The environment was monitored and these samples were removed after nine months having been exposed to typical tokamak operations. General Atomics has collated the enviornmental data that will be used to provide a preliminary assessment of the behavior of the alloy in the tokamak environment. ANL is performing an evaluation of the specimens. During the January 1996 vent, a second set of CVN and tensile specimens were installed in DIII-D and exposure will continue until the next vent.

In parallel, other vanadium alloy samples were exposed utilizing the DIII-D Divertor Material Exposure System (DiMES), which allows for short term exposure and does not require a vent to retrieve the samples. A postvent bake cycle represents what is expected to be the most severe environmental condition. Therefore, a vanadium alloy disc was exposed during the initial baking and

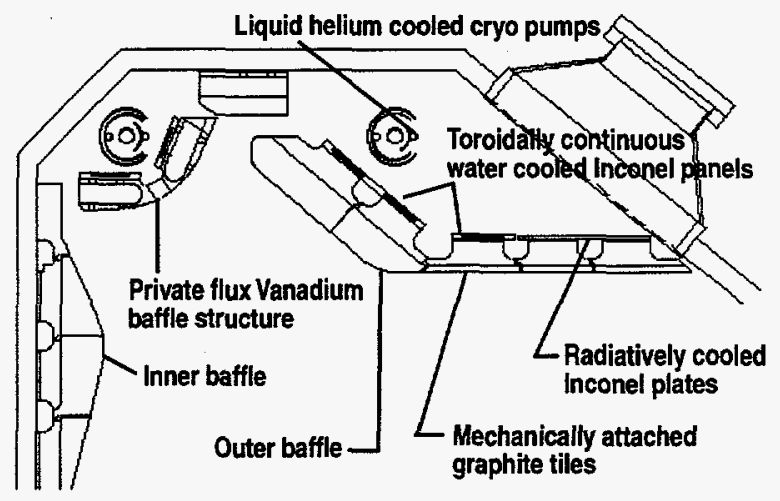

Fig. 1. Location of vanadium structure in radiative divertor.

cleaning of DIII-D after the February 1995 vent. The disc is currently being analyzed at ANL to determine the pickup of any impurities. Additional exposure of five minature CVN specimens to a similar baking cycle was performed in July 1995, and evaluation is occuring at ANL. Other DiMES exposures are planned to evaluate the specific effects of other DIII-D environmental conditions such as discharge cleaning and boronization.

\section{B. Phase 2: Small Component Exposure}

A second step in the DIII-D Vanadium Plan is to install a small vanadium alloy component in DIII-D. This component will be manufactured utilizing many of the methods proposed for the Phase 3 water-cooled structural panels. The component will be installed, exposed for some period of tokamak operations, and removed. Samples from the component will be excised and metallurgical analyses and property measurements will be made.

\section{Phase 3: Radiative Divertor Program}

The design, manufacture, and installation of a vanadium private flux baffle structure for the upper divertor of the RDP will be done as the third phase of the vanadium alloy program. The vanadium alloy structure consists of toroidally-continuous, water-cooled structural panels with graphite tiles mechanically attached to make the plasma facing surface. The panels will be water cooled during tokamak operations, experiencing a maximum temperature of $\sim 60^{\circ} \mathrm{C}$, but during baking of the vacuum vessel, hot air will replace the water in the structure and it will be baked to $400^{\circ} \mathrm{C}$. Due to the lower electrical resistivity of the $\mathrm{V}-4 \mathrm{Cr}-4 \mathrm{Ti}$ alloy compared to the Inconel 625 components, the toroidal current flow during plasma disruption will be approximately 4 times larger than in other RDP components. The design of the panels and supports will be modified to react the larger loads. 
Each panel will be made in six segments, fabricated by welding two $4.8 \mathrm{~mm}$ sheets creating an internal coolant channel. Resistance seam welding will provide the strength for the panels while a perimeter electron beam weld would make the vacuum seal. Other methods of joining are proposed for different areas of the design. To facilitate installation, bi-metallic tube joints are planned so that all field welds will be Inconel to Inconel.

\section{PRODUCTION OF VANADIUM ALLOY}

A heat of vanadium alloy is required for the fabrication of the RDP project. In preparation for the production, a detailed material specification was written for $\mathrm{V}-4 \mathrm{Cr}-4 \mathrm{Ti}$ alloy from the starting material all the way to completion of product forms. The alloy $\mathrm{V}-4 \mathrm{Cr}-4 \mathrm{Ti}$ is presently selected by the U.S. fusion materials program. The specification outlined the production steps along with control and quality tests required. This specification was written by General Atomics with assistance from Teledyne Wah Chang Albany (TWCA), ANL and ORNL. Goals for the levels of impurities were specified, with a focus on keeping the levels of potentially embrittling elements $(\mathrm{O}, \mathrm{N}, \mathrm{C}$, etc.) low. Consideration was also given to minimizing the levels of $\mathrm{Nb}, \mathrm{Mo}, \mathrm{Ag}$. In the future low levels of these elements will be required to achieve low activation properties for the material. Processing started in September of 1995 with the selection of raw vanadium derbies to be electron beam melted into two pure vanadium ingots. Two ingots were electron beam melted; one $(900 \mathrm{~kg})$ and the other $(\sim 1000 \mathrm{~kg})$. Samples were taken from the two ingots for chemical analysis and for rolling by ORNL into sheet and machining into Charpy Vnotch (CVN) specimens by ANL. Impact testing at $-196^{\circ} \mathrm{C}$ was performed to evaluate ductility. The data agreed reasonably with test results for the raw material used for the $500 \mathrm{~kg} \mathrm{~V}-4 \mathrm{Cr}-4 \mathrm{Ti}$ alloy ingot.

The entire $900 \mathrm{~kg}$ ingot was chipped and blended with $400 \mathrm{~kg}$ of the second ingot to produce approximately $1200 \mathrm{~kg}$ of vanadium alloy. The consolidation of the vanadium along with high purity chromium and double vacuum melted titanium proceeded in February 1996. The ingot was vacuum arc melted twice to form a $1200 \mathrm{~kg}$ $\mathrm{V}-4 \mathrm{Cr}-4 \mathrm{Ti}$ ingot.

The outside diameter of the ingot was machined and cut into two pieces for vacuum canning in stainless steel for extrusion into sheet bar. The material was extruded into $\sim 4 \mathrm{in} . \times 10 \mathrm{in}$. sheet bar at $1150^{\circ} \mathrm{C}$. The first extrusion was processed successfully but the second stalled roughly half way through the die. The vacuum can was not breeched during processing, and the material was not compromised. Estimates revealed that enough material was produced to meet the needs of the RDP program. The remaining pieces of the ingot can be processed further at a later date if necessary.

The next step in the processing will be the warm cross-rolling of the extrusion into $4.8 \mathrm{~mm}$ plate and machining and swaging into $0.4 \mathrm{in}$. diameter rod. Completion of the product forms is scheduled for late summer of 1996 .

\section{JOINING DEVELOPMENT}

As most of the work within the fusion vanadium program has been focused on alloy development and irradiation properties, a key goal of the DIII-D vanadium program was to develop manufacturing techniques. For the success of the RDP program, welding and joining process development is important. Vanadium, being a refractory metal, is highly susceptible to embrittlement by oxygen, nitrogen, carbon, and hydrogen, at elevated temperatures, and most welding has required a high purity protective environment. Welding studies on gas Tungsten arc (GTA), e-beam, and laser welding are ongoing at ANL and ORNL but additional processes are required for the DIII-D program. Thus, studies have been initiated on resistance, friction, stud, and electron beam welding techniques of vanadium alloys.

\section{A. Resistance Welding}

Resistance welding is planned for structurally joining two sheets of vanadium together to make the water-cooled panels for the RDP. It will not provide the vacuum-tight weld, however. Initial spot welding trails were made, joining $1 \mathrm{~mm}$ thick sheets together. These trials were made in air and produced a weld nugget with microhardness only $10 \%$ greater than the bulk material. This was a very promising result, in that a protective atmosphere may not be required. A parameter search of pressure and current for welds of thicker material was started. No weld nugget was achieved on $3.8 \mathrm{~mm}$ sheet, based on parameters for welding Inconel, although the diffusion bond demonstrated considerable strength (up to $135 \mathrm{MPa}$ ) in crude shear tests.

It was then decided to use carbon steel parameters as the next reference point, due to similar resistivity and strength. These trials were successful, forming weld nuggets approximately $7 \mathrm{~mm}$ in diameter (Fig. 2). Microhardness measurements showed less than a $10 \%$ increase in hardness. Spot weld trials were then performed on $4.8 \mathrm{~mm}$ thick material, the thickness of the RDP sheets, and were also successful. The strength of these spot welds are being evaluated and resistance seam welding trails are being planned. 

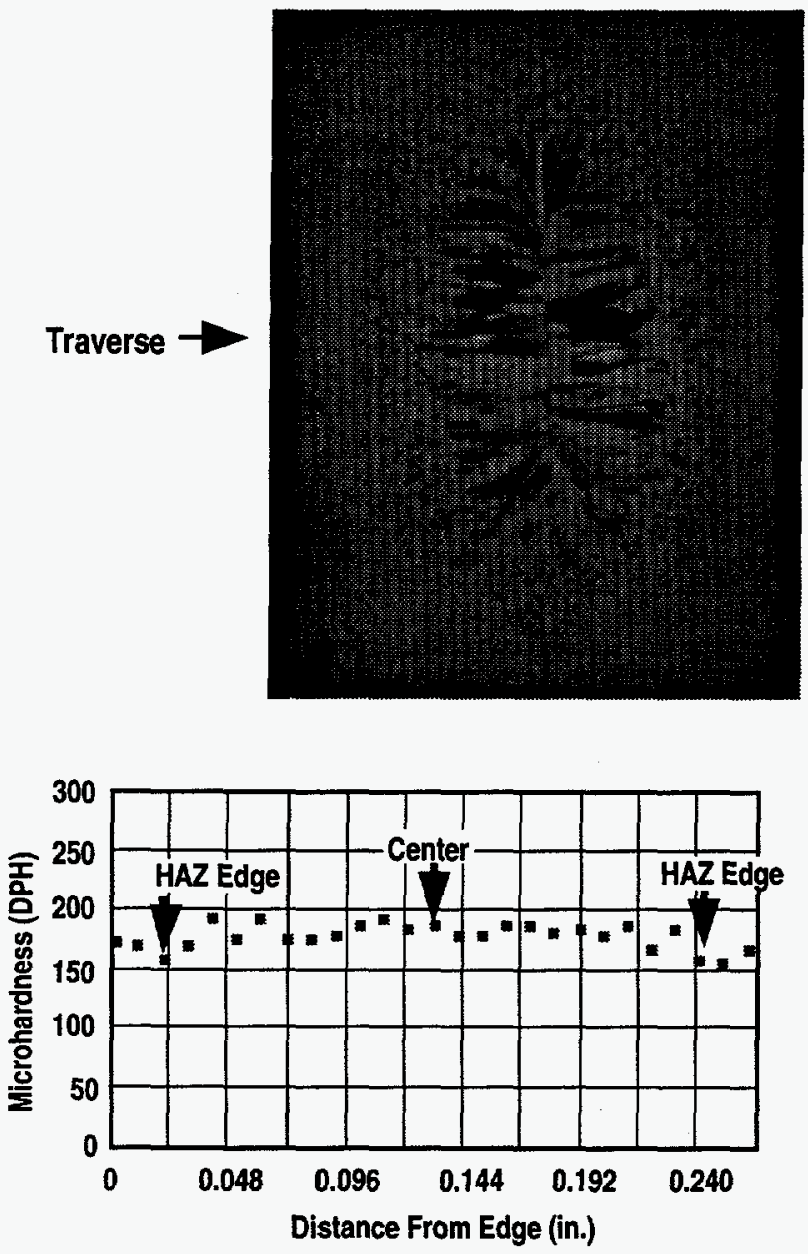

Fig. 2. Resistance spot weld of $3.8 \mathrm{~mm}$ thick $\mathrm{V}-4 \mathrm{Cr}-4 \mathrm{Ti}$ alloy sheets with microhardness profile across the weld nugget.

\section{B. Friction Welding Studies}

Two types of friction welding trials are in progress. Inertia and portable friction welding will be used for joining vanadium alloy to itself, and inertia welding for creating a bi-metallic joint. The first inertia weld trials of vanadium rod to vanadium plate were successful in air, without any protective environment. Metallography showed complete bonding with no indications of porosity or cracking. Microhardness measurements showed only slight increases in hardness in the weld and heat affected zones (HAZ). In this process, the temperature is kept below melting and can better be described as a hot forging process rather than welding. The interface maintained a fine grain structure, with little or no grain growth (Fig. 3). Tensile and torsion tests resulted in failures in the parent material away from the joint and $\mathrm{HAZ}$.

Trials continued with evaluation of the joining of Inconel 625 to vanadium alloy. A bi-metallic joint would allow for field welding of only Inconel components in
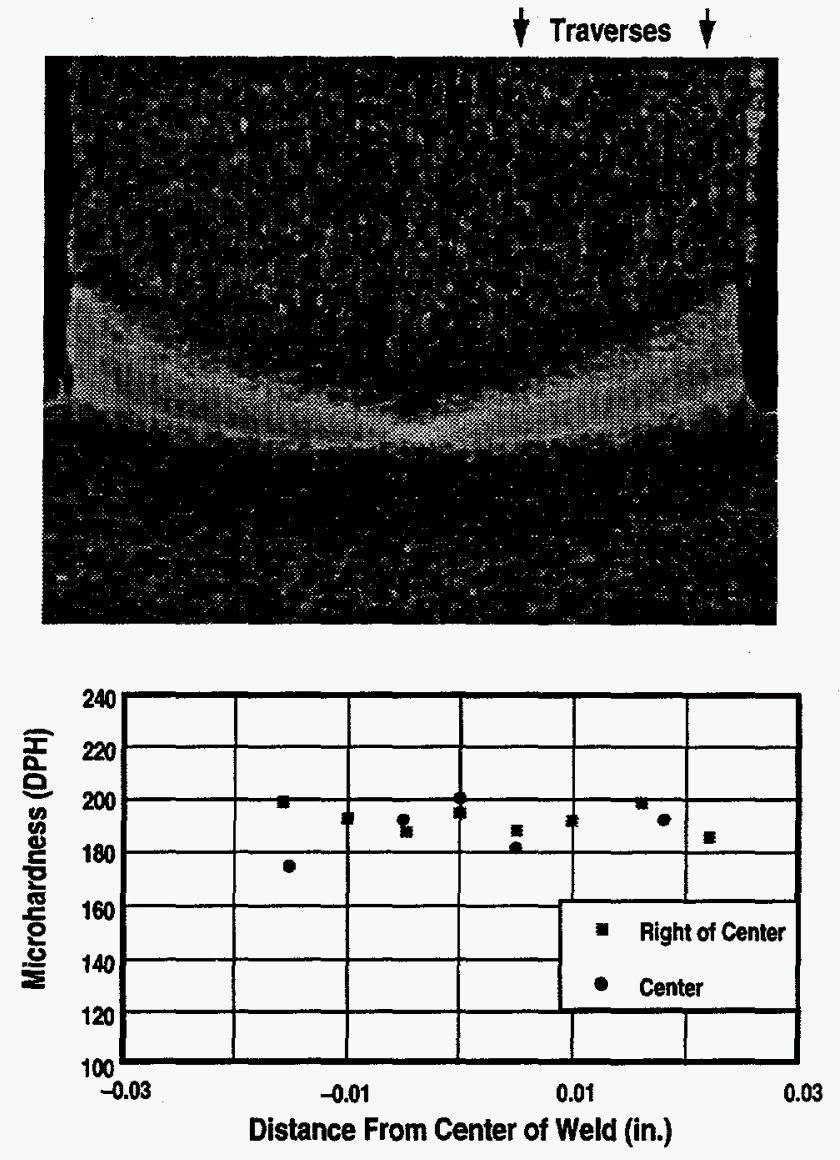

Fig. 3. Etched cross-section of V-5Cr-5Ti alloy inertial weld trial sample showing location of weld joint and microhardness measurements.

DIII-D with all vanadium welds carefully characterized in the shop. Some bonding was achieved on the first samples but full strength was not developed. Additional trials using different diameter rods for the two materials, attempting to match the forgabilities, were successful. Metallography showed complete bonding with no porosity or cracking in the joint. Tensile pull tests were performed on three weld trial samples. Two samples failed in the Inconel 625 section well away from the weld area (at $\sim 930 \mathrm{MPa}$ stress) and one sample failed at the approximate weld interface, at a stress level of $\sim 760 \mathrm{MPa}$. With the joining ability of the two materials demonstrated, the development was shifted to creating a bi-metallic tube joint. These trials have now been performed, and tests to evaluate their strength and leak tightness are in progress.

Preliminary portable friction welding trials of rod to plate have been performed to develop methods of in-situ replacement of studs on the water cooled panels. The initial trials achieved substantial bonding but hardness of the weld interface increased significantly. In addition, large grain growth occurred at the interface and heat 
affected zone (Fig. 4). It was noted that in the trials, the temperature of the interface was significantly higher than in the inertia weld process and the time to create the weld was longer. It was believed that both of these factors led to the grain growth and increase in hardness. Additional trials are in progress.

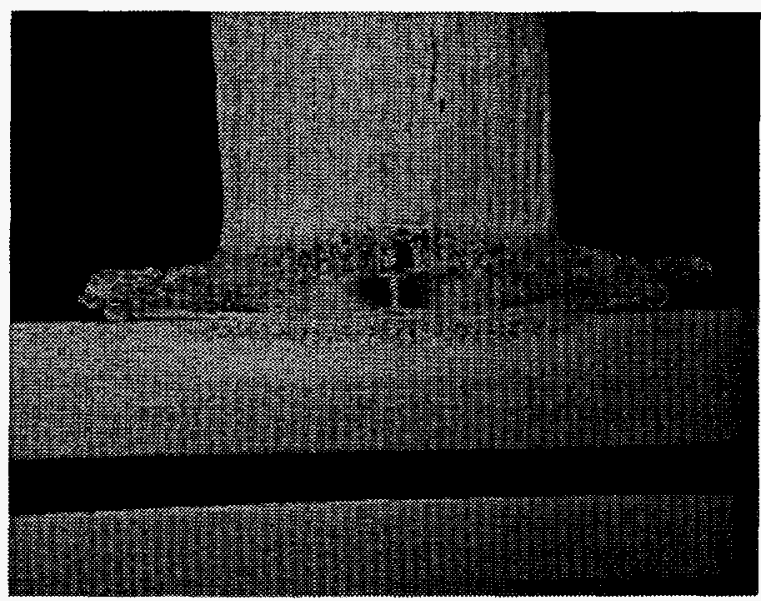

Fig. 4. Etched cross-section of V-5Cr-5Ti alloy portable friction weld trial sample showing location of weld joint.

\section{Stud Welding Studies}

Stud welding trials utilizing a drawn arc method were performed between vanadium alloy stud and plate materials. A range of welding parameters was used without success. The molten material was consistently blown out of the interface zone and little or no bond was achieved. Audible cracking was noted during cool down of the materials indicating a pick up of impurities, embrittling the material. A second set of trials utilizing a different stud geometry was performed, but was also unsuccessful. These failures, and the successes achieved in the vanadium alloy inertial weld trials, prompted the investigation of the portable friction welding previously described as the process for attachment of the studs.

\section{Electron Beam Welding Studies}

Preliminary electron beam welding trials have also been initiated at General Atomics to complement the work being performed at ORNL. Initial weld parameters were obtained from ORNL and weld penetration tests performed using $6.35 \mathrm{~mm}$ thick vanadium alloy plate. These trials established specific weld parameters for creating a lap weld of two $3.85 \mathrm{~mm}$ thick vanadium alloy sheets. The lap weld, once created, was metallurgically examined. Good weld penetration was obtained with no indications of cracking or porosity. Microhardness measurements showed less than $\sim 10 \%$ increase in hardness. A weld was made in a single sheet to produce three tensile specimens to develop strength data on the weld. The tensile specimens all failed in the parent material well away from the weld joint and $\mathrm{HAZ}$ at values equal to the yield strength of the material.

\section{TUBING FABRICATION}

General Atomics has designed and manufactured a high heat flux test module made from vanadium alloy. The module is helium-cooled and is designed to handle an incident heat flux up to $3 \mathrm{MW} / \mathrm{m}^{2}$. The vanadium tube was manufactured by cold drawing a machined tube blank. The starting material was $29 \mathrm{~mm} \mathrm{V-4Cr}-4 \mathrm{Ti}$ plate. The drawing process required a total reduction of $50 \%$ with an intermediate vacuum anneal after $30 \%$ reduction. After drawing, the inside diameter had axial grooves electro discharge machined for heat transfer enhancement. A swirl rod insert made from stainless steel, was placed in the bore to create annular helium flow. Testing of the module is planned for July 1996.

\section{CONCLUSIONS}

A program for utilizing vanadium alloys in DIII-D has been developed to enhance the development of low activation vanadium alloys for fusion. The production of $1200 \mathrm{~kg}$ of material for this program is in progress. Two vanadium ingots have been electron beam melted as base materials for the $-1200-\mathrm{kg} \mathrm{V}-4 \mathrm{Cr}-4 \mathrm{Ti}$ alloy ingot. The alloy ingot has been double vacuum arc melted and extruded into sheet bar. Preliminary successes have been achieved in developing welds in vanadium alloy using resistance, inertia, friction, and electron beam welding methods. Fabrication of tubing was demonstrated with the production of a high heat flux test module.

\section{ACKNOWLEDGEMENTS}

This is a report of work supported by General Atomics internal R\&D funding and the U.S. Department of Energy under Contract No. DE-AC03-89ER51114 and. The authors would like to acknowledge Teledyne Wah Chang Albany for their efforts producing the vanadium alloy material, Interface Welding for inertia welding work, and to RAM Stud for friction welding work. 


\section{DISCLAIMER}

This report was prepared as an account of work sponsored by an agency of the United States Government. Neither the United States Government nor any agency thereof, nor any of their employees, makes any warranty, express or implied, or assumes any legal liability or responsibility for the accuracy, completeness, or usefulness of any information, apparatus, product, or process disclosed, or represents that its use would not infringe privately owned rights. Reference herein to any specific commercial product, process, or service by trade name, trademark, manufacturer, or otherwise, does not necessarily constitute or imply its endorsement, recommendation, or favoring by the United States Government or any agency thereof. The views and opinions of authors expressed herein do not necessarily state or reflect those of the United States Government or any agency thereof. 